\title{
The Effectiveness of Phototherapy with Low Cost White Curtains versus Routine Phototherapy among Newborns Admitted with Neonatal Jaundice
}

\author{
Simi Elsa Philip ${ }^{1}$, Rajashri B. Karale ${ }^{2}$ \\ ${ }^{1}$ Msc $2{ }^{\text {nd }}$ year student, Department Of Child Health Nursing, Krishna Institute of Nursing Science, KIMSDU, Dhebewadi Road, Malkapur- \\ 415539, Karad(Maharashtra) India. \\ ${ }^{2}$ Lecturer, Department Of Child Health Nursing, Krishna Institute of Nursing Science, KIMSDU, Dhebewadi Road, Malkapur-415539, \\ Karad(Maharashtra) India
}

\begin{abstract}
Neonatal jaundice is an important problem in the first week of life. Approximately $70 \%$ of term and $80 \%$ of preterm babies develop jaundice in the first week of life, and about $10 \%$ of breastfed babies are still jaundiced at 1 month of age. Purpose: To study The Effectiveness Of Phototherapy With Low Cost White Curtains Versus Routine Phototherapy Among Newborns Admitted With Neonatal Jaundice. Materials and methods: Experimental study with two group pre -test-post -test design was used to compare the effectiveness of phototherapy with low cost white curtain $(n=30)$ versus routine phototherapy without curtain $(n=30)$ in NICU at Krishna hospital, Karad. Data collection tools included, Kramer scale and Laboratory investigation, observation checklist regarding selected behavioral and physiological responses. Result: The decrease of median total serum bilirubin levels after 24 and 48 hours of phototherapy was significantly greater in the experimental group (14.4 and 13.8 respectively) than in the control group ( 13.85 and 12.15 respectively), both $P<0.0001$. It was found that the baseline and demographic characteristics between the 2 groups were statistically no significant ( $p$ $>0.05)$. Conclusion: Hanging low cost white curtains around phototherapy units significantly increases efficacy of phototherapy in the treatment of neonatal jaundice without evidence of any adverse effects.
\end{abstract}

Keywords: Routine Phototherapy, Neonates, Neonatal Jaundice, Low cost white curtain, NICU

\section{Introduction}

Neonatal jaundice is an important problem in the first week of life. Approximately $70 \%$ of term and $80 \%$ of preterm babies develop jaundice in the first week of life, and about $10 \%$ of breastfed babies are still jaundiced at 1 month of age. Neonatal jaundice refers to yellow coloration of the skin and the sclera of new born babies that result from accumulation of bilirubin in the skin and mucous membranes. This is associated with a raised level of bilirubin in the circulation, a condition known as hyperbilirubinaemia $^{(1)}$ The nurse is responsible for assessing all newborns for the presence of jaundice as a part of physical assessment. These examinations should be done in natural day light. The color of the nails, sclera, mucus membrane and skin including palms and soles are observed. Applying direct pressure to the skin especially over bone prominences such as the tip of the sternum, causes blanching and allow the yellow stain to be more pronounced ${ }^{(2)}$. Phototherapy is non -invasive, inexpensive and easy method of degradation of unconjugated bilirubin by photo-oxidation. The light ways convert the toxic bilirubin into water soluble non toxic form which is easily excreted from the blood in the bile, stool and urine ${ }^{(3)}$.

\section{Review of Literature}

1) Dr. Akrem MA (2015).A case- control study conducted at Maternity and Obstetric Hospital in Duhok, North of Iraq from January to October 2014 and they use white curtains that was made of white paper around phototherapy units and see whether this is effective..
Results was the overall rate of lowering of serum bilirubin in cases with white curtains is $0.85 \mathrm{mg} / \mathrm{dl} / 4 \mathrm{hrs}$ versus $0.76 \mathrm{mg} / \mathrm{dl} .4 \mathrm{hrs}$ in controls. The rate of TSB lowering incases is significantly higher than in controls in most of weight groups ${ }^{(4)}$

2) Homa B et al in Iran on 2013 to determine the effect of adding white plastic cover around the phototherapy unit on hyperbilirubinemia in full term neonates with jaundice through 182 term neonates. The result shows that Total serum bilirubin in covered group, during the first 48 hours of treatment, declined significantly than in control group $(P$ value $=0.003){ }^{(5)}$

3) Djokomulijanto et al on 2006 in Malaysia conduct study to evaluate the effect of white curtains around phototherapy unit through studying 97 newborns. The results showed that the rate of bilirubin level decrease in case group $(25.24 \mu \mathrm{mole} / \mathrm{l})$ was significantly greater than in control group $(24.27 \mu \mathrm{mole} / 1)(P<0.001)^{(6)}$.

\section{Methodology}

Experimental study with two group pre -test -post -test design was undertaken after institutional ethical committee approval to compare the effectiveness of phototherapy with low cost white curtain versus routine phototherapy among newborns admitted with neonatal Jaundice. The sample size for the study was 60 . The samples were from the NICU at 1150 beded, Tertiary level hospital - Krishna Hospital, Karad, Maharashtra with 30 beded NICU accredited by NNF. The duration of study was 1 month. 


\section{International Journal of Science and Research (IJSR) \\ ISSN (Online): 2319-7064}

Index Copernicus Value (2013): 6.14 | Impact Factor (2015): 6.391

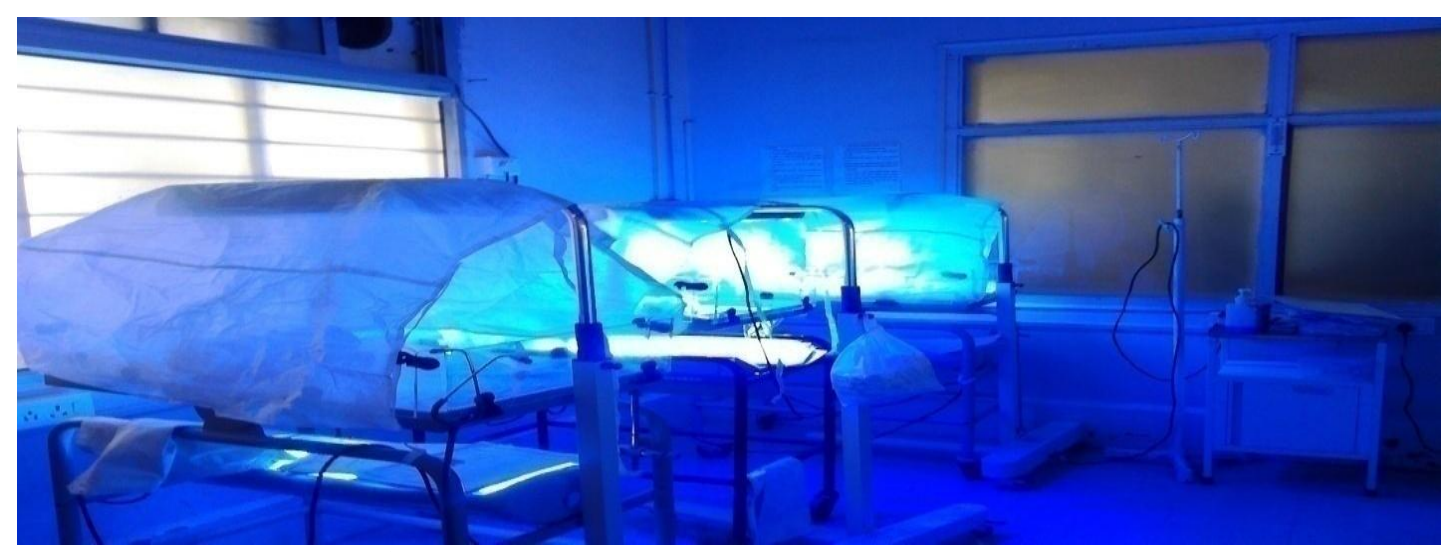

Figure 1: Phototherapy with low lost white curtains

The curtains was made up of low cost soft cotton cloths which is white in color, height of $48 \mathrm{~cm}$, length of $66 \mathrm{~cm}$, width of $36 \mathrm{~cm}$ which is covered three sides of the phototherapy unit, front side was uncovered or kept open for observation of the baby and performing procedures.

Inclusion criteria: Neonates with who have hyperbilirubinaemia, requiring single photo therapy, gestational age above 32 weeks, weight above 1500 and physiologically stable are included in the study.

Exclusion criteria: Neonates who are having congenital abnormalities and critically ill, who had serum bilirubin levels close to the exchange transfusion limit and require double surface phototherapy are excluded.

\section{Description of the Tool}

Section I: Demographic profile Section one was prepared to collect general information about the mother and neonate. A structured questionnaire used, which includes demographic variables such as age, education, consanguineous marriage, gravida status, any medical illness during pregnancy, blood group and Rh incompatibility of mother and for the baby includes age in hours, sex, weight, first feed, blood group, Rh incompatibility, type of jaundice.

\section{Section II: Observation Checklist Regarding Sign And Symptoms Of Jaundice By Using Kramer's Scale : Kramer's scale describe the appropriate SBR-Serum Bilirubin level with the level of skin discoloration. Kramer divided the infant into 5 zones. The skin should be blanched with digital pressure and the underlying color of skin and subcutaneous tissue should be noted. Observation checklist regarding signs and symptoms of jaundice were assessed for before intervention and after intervention 24 hours and 48 hours with neonates placed in appropriate zone.}

Section III: Bilirubin assessment in reference with Laboratory Investigation : Neonates Serum bilirubin level checked before intervention and post intervention after 24 hours and 48 hours.

Section IV: observation checklist regarding selected behavioral responses includes sucking or feeding, cry, sleepiness of neonate and selected physiological responses of axillary temperature, respiration and heart rate are checked before intervention and after intervention every $6^{\text {th }}$ hourly upto 48 hours.

\section{Results}

\section{Section I Demographic profile}

Mother: In Experimental group, among 30, maximum subjects 14 (46.7\%) of them were between the 21-25 years and $25(83.3 \%)$ had non consanguineous marriages. Majority subjects 15 (50\%) had normal delivery. Maximum subjects 17 (56.7\%) had no illnesses. Most subjects 12 (40\%) had „Ö Blood group and maximum subjects 23 (76.7\%) had $\mathrm{Rh}$ positive Blood group. In the control group, among 30, maximum subjects 17 (56.7\%) were between 21-25 years age group and $27(90 \%)$ had non consanguineous marriage. Majority subjects 20 (66.7\%) had normal delivery. Maximum subjects 17 (56.7\%) had no illnesses. Most subjects $11(36.7 \%)$ had „O $\mathrm{O}^{\text {ee }}$ Blood group and maximum subjects 23 (76.7\%) had Rh positive Blood group.

Neonates: In Experimental group Maximum subjects 16 (53.3\%) were males with majority subjects 15 (50\%) had age of $49^{\text {th }}$ hours to $72^{\text {nd }}$ hours. Highest subjects $17(56.7 \%)$ belong to $>2500 \mathrm{gm}$. Maximum subject $10(33.3 \%)$ had ,A $\mathrm{A}^{\text {ee }}$ blood group and majority $21(70 \%)$ had Rh positive blood group. Maximum 29(96.7\%) had physiological jaundice. In the control group, Maximum subjects 16 (53.3\%) were females. With majority subjects $14(46.7 \%)$ of had age of $49^{\text {th }}$ to $72^{\text {nd }}$ hours. Highest subjects $15(50 \%)$ belong to 2000 2499 grams. Maximum 10(33.3\%) had „O $\mathrm{O}^{\text {ce }}$ blood group and majority 20(66.7\%) had Rh positive blood group. Maximum subjects 29(96.7\%) had physiological jaundice. 


\section{International Journal of Science and Research (IJSR) \\ ISSN (Online): 2319-7064}

Index Copernicus Value (2013): 6.14 | Impact Factor (2015): 6.391

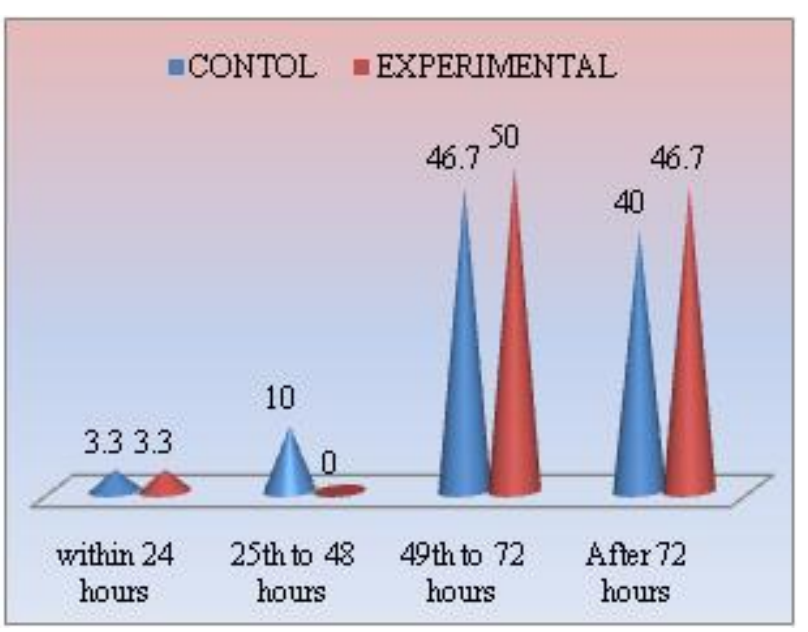

Figure 2: Distribution of samples in relation to age in hours

Cone graph shows that in both the groups majority of neonates are in the age group of $48^{\text {th }}-72^{\text {nd }}$ hours after delivery

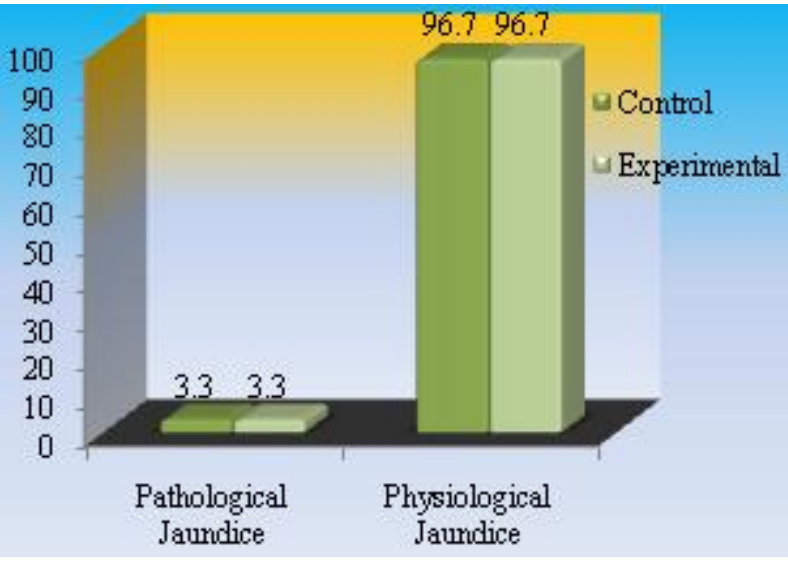

Figure 3: Distribution of sample in relation to type of jaundice

Bar diagram shows that in both the groups majority of neonates are more prone for physiological jaundice.

Section II: Effect of white curtains on efficiency of phototherapy on Kramer's scale for sign and symptoms of jaundice within the control and experimental group. $(\mathbf{n}=60)$

Table 1: Effect of white curtains on efficiency of phototherapy on Kramer"s scale within the control and experimental group

\begin{tabular}{|c|c|c|c|c|}
\hline \multirow{2}{*}{ Readings } & \multicolumn{2}{|c|}{ Control Group } & \multicolumn{2}{c|}{$\begin{array}{c}\text { Experimental } \\
\text { Group }\end{array}$} \\
\cline { 2 - 5 } & $\begin{array}{c}\text { Sum of } \\
\text { Ranks }\end{array}$ & Median & $\begin{array}{c}\text { Sum of } \\
\text { Ranks }\end{array}$ & Median \\
\hline 0 Hour (Pre Intervention) & 77.5 & 4 & 87 & 5 \\
\hline 24 Hours & 60.5 & 4 & 62.5 & 4 \\
\hline 48 Hours (Post Intervention) & 42 & 3 & 30.5 & 5 \\
\hline Friedman Statistic & \multicolumn{2}{|c|}{30.39} & \multicolumn{2}{c|}{56.83} \\
\hline p- value & \multicolumn{2}{|c|}{$<0.0001$} & \multicolumn{2}{c|}{$<0.0001$} \\
\hline
\end{tabular}

It revealed that, there was significant reduction in Serum Bilirubin level for Kramers scale after 24 hours and 48 hours (post intervention) for both control and experimental groups $(\mathrm{p}<0.0001)$. In experimental group in post test, subjects from level 5 shifted to $2^{\text {nd }}$ and $3^{\text {rd }}$ zone, which shows the effectiveness of the phototherapy whereas in control group in post test, subjects from level 5 shifted to $4^{\text {th }}$ and $3^{\text {rd }}$ zone, which was very less numbers compare to experimental group.

In view of above it can be noted that there was significant improvement in efficiency of phototherapy with the use of white curtains in experimental group than control group, as the reduction of sum of ranks in total serum bilirubin levels from 0 hour (pre intervention) to 48 hours (post intervention) of phototherapy was significantly greater in the experimental group (87 to 30.5 respectively) than in the control group (77.5 to 42 respectively), both $\mathrm{P}<0.0001$.

Section III: To determine the serum bilirubin level of the neonate with neonatal jaundice in experimental group and control group in reference with Laboratory Investigations.

Table 2: Distribution of samples according to laboratory serum bilirubin level

\begin{tabular}{|c|c|c|c|c|}
\hline \multirow{2}{*}{ Readings } & \multicolumn{2}{|c|}{ Control Group } & \multicolumn{2}{c|}{ Experimental Group } \\
\cline { 2 - 5 } & $\begin{array}{c}\text { Sum of } \\
\text { Ranks }\end{array}$ & $\begin{array}{c}\text { Media } \\
\mathrm{n}\end{array}$ & $\begin{array}{c}\text { Sum of } \\
\text { Ranks }\end{array}$ & Median \\
\hline $\begin{array}{c}\text { 0 Hour (Pre } \\
\text { Intervention) }\end{array}$ & 85 & 15.5 & 90 & 15.9 \\
\hline 24 Hours & 65 & 14.4 & 60 & 13.85 \\
\hline $\begin{array}{c}\text { 48 Hours (Post } \\
\text { Intervention) }\end{array}$ & 30 & 13.8 & 30 & 12.15 \\
\hline Friedman Statistic & \multicolumn{2}{|c|}{51.67} & \multicolumn{2}{|c|}{60} \\
\hline p- value & \multicolumn{2}{|c|}{$<0.001$} & \multicolumn{2}{c|}{$<0.0001$} \\
\hline
\end{tabular}

It revealed that, there was significant reduction in Serum bilirubin, after 24 hours and 48 hours (post intervention) for both control and experimental groups $(\mathrm{p}<0.0001)$. It was found that, for control group, there was significant reduction in Serum bilirubin from pre intervention to 48 hours (post intervention) $(\mathrm{p}<0.001)$ and from 24 hours to 48 hours $(p<0.01)$.For experimental group, there was significant reduction in Serum bilirubin from pre intervention to 24 hours and 48 hours (post intervention) and also in 24 hours to 48 hours $(\mathrm{p}<0.001)$. In view of above it can be noted that there was significant improvement in efficiency of phototherapy with the use of white curtains in experimental group than control group, as reduction in median serum bilirubin level was more in experimental group as compared to control group.

Section IV Physiological And Behavioral Response : There was no significant difference between control and experimental groups for physiological and behavioral responses for different interventions ( $\mathrm{p}>0.05$ ).

\section{Discussion}

The findings of present study have been discussed with reference to the objectives and hypothesis. A findings of the study shows that both the interventions - routine phototherapy and phototherapy with low cost white curtains were significantly effective for reducing serum bilirubin level in the babies with neonatal jaundice. Whereas phototherapy with white low cost curtains is slightly more effective than the routine phototherapy in reducing serum bilirubin level in neonates with neonatal jaundice. 


\section{International Journal of Science and Research (IJSR) \\ ISSN (Online): 2319-7064 \\ Index Copernicus Value (2013): 6.14 | Impact Factor (2015): 6.391}

Supporting studies show results compatible with the findings of our Study was Ari Kurniashi et al in 2011 conducted a randomized, controlled, open trial in Medan through 60 term newborns to find the effectiveness of phototherapy with reflecting curtains on neonatal jaundice. The Results shows that the decrease of total serum bilirubin level after $12^{\text {th }}$ hours and $24^{\text {th }}$ hours of phototherapy was significantly greater in the study group (3.71 and $9.7 \mathrm{mg} / \mathrm{dl}$, respectively) than in the control group ( 0.1 and $3.8 \mathrm{mg} / \mathrm{dl}$, respectively ), both $\mathrm{P}<0.05$. $^{(7)}$

\section{Conclusion}

Hanging low cost white curtains around phototherapy units significantly increases efficacy of phototherapy in the treatment of neonatal jaundice without evidence of any adverse effects.

\section{Future Scope}

Similar study can be done on a large subjects. More researches need to be undertaken to compare the incidence of neonatal jaundice and effectiveness of Phototherapy with white low cost curtains or other methods, this method can be use as routine practices because cost of curtains are very low, can be reuse after washing and sterilization without any adverse effects..A follow up study can be conducted to evaluate the adherence to treatment to the particular intervention.

\section{Acknowledgement}

The Author is thankful to administrative authority of Krishna Institute of Nursing Science and Krishna Hospital, Karad, Head of Department of Paediatrics Doctor Aundhakar Sir and Dr.Ingale Sir for their guidance cooperation and support.

\section{References}

[1] Parthasarthy Menon, Piyush Nair.'IAP textbook of pediatric". Jaypee Brothers Medical Publishers (p)ltd, New Delhi. $5^{\text {th }}$ ed. p: 41.

[2] BT Basavanthappa."Child Health Nursing".The Health Sciences Publishers.p: 32.

[3] Parul Dutta." Pediatric Nursing". $2^{\text {nd }}$ ed. Jaypee Brothers Medical Publishers, p: 100.

[4] Dr. Akrem M. Atrushi. " The effect of white curtains around phototherapy unit on the efficacy of phototherapy in the treatment of neonatal hyperbilirubinemia in Duhok".Global journal for research analysis, Vol-4, Issue-6, June-2015

[5] Homa Babaei, Ali-Asghar Alipour, Mitra Hemmati, Mohammad Ghaderi, and Mansour Rezaei."Effect of White Plastic Cover around the Phototherapy Unit on Hyperbilirubinemia in Full Term Neonates".. Iran Journal of Pediatrics. 2013 Apr; 23(2): 143-148. Available from URL: www.ncbi.nlm.nih.gov > NCBI > Literature, PubMed Central (PMC. Accessed on $10 / 27 / 15$ at $2.07 \mathrm{pm}$

[6] S Djokomuljanto, B S Quah, Y Surini, R Noraida, N Z $\mathrm{N}$ Ismail, $\mathrm{T} \mathrm{W} \mathrm{R}$ Hansen, and $\mathrm{H}$ Van
Rostenberghe."Efficacy of phototherapy for neonatal jaundice is increased by the use of low-cost white reflecting curtains". ADC Fetal and neonatal editiv.91(6); 2006 Nov.Available from URL : www.ncbi.nlm.nih.gov > NCBI > Literature > PubMed Central. Accessed on 10/27/15 at 2.10 pm

[7] Ari K, Guslihan D T, Muhammad A, Emil A, Pertin S." Effectiveness of phototherapy with reflecting curtains on neonatal jaundice “. Pediatric Indonesiana.2011 sep, Vol -51, p;256-61.

\section{Author Profile}

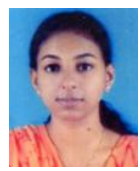

Simi Elsa Philip is $2^{\text {nd }}$ year Msc Nursing SStudent.Dept of Child Health Nursing. Krishna Institute of Nursing Science, KIMSDU, Karad -41553, Maharashtra.

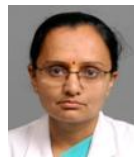

Rajashri B. Karale is lecturer. Dept of Child Health Nursing since 2010. Krishna Institute of Nursing Science, KIMSDU, Karad -41553, Maharashtra. She worked in clinical areas 14 years including 8 years in NICU. 